\title{
Mental Health Needs in Vietnamese American Communities Affected by the Gulf Oil Spill
}

\author{
Dung $\mathrm{Ngo}^{1^{*}}$, Judith L. Gibbons ${ }^{2}$, Grace Scire ${ }^{3}$, Daniel Le ${ }^{4}$ \\ ${ }^{1}$ Department of Psychology, The University of Texas at Tyler, Tyler, USA \\ ${ }^{2}$ Department of Psychology, Saint Louis University, St. Louis, USA \\ ${ }^{3}$ Boat People SOS, Gulf Coast Region, Bayou La Batre, USA \\ ${ }^{4}$ Boat People SOS, Gulf Coast Region, Biloxi, USA \\ Email: *dngo@uttyler.edu
}

Received November 23 $3^{\text {rd }}$, 2013; revised December 22 ${ }^{\text {nd }}$, 2013; accepted January $18^{\text {th }}, 2014$

Copyright (c) 2014 Dung Ngo et al. This is an open access article distributed under the Creative Commons Attribution License, which permits unrestricted use, distribution, and reproduction in any medium, provided the original work is properly cited. In accordance of the Creative Commons Attribution License all Copyrights (C) 2014 are reserved for SCIRP and the owner of the intellectual property Dung Ngo et al. All Copyright ( 2014 are guarded by law and by SCIRP as a guardian.

Background: The Vietnamese American Gulf Coast communities have experienced recent disasters, including both hurricane Katrina and the Deepwater Horizon (BP) Oil Spill. The objectives of this study were to examine the impact of the 2010 Deepwater Horizon Oil Spill on the Vietnamese American Gulf Coast communities and to offer recommendations on how to effectively work with this underserved population. Method: Focus groups were held with Vietnamese coastal residents of three affected Gulf Coast US States (Alabama, Louisiana, and Mississippi) to assess the impact of the oil spill disaster in the areas of economic hardship, family functioning, and behavioral and mental health issues. Sixty Vietnamese-speaking individuals (65\% females) with an age range from 28 - 65 years who had an average of eight years of education participated in the study. Approximately $77 \%$ had worked in the seafood industry and about 92\% indicated that they spoke English "not very well”. Audio recordings of the focus group discussions were transcribed, recorded on a spread sheet, and categorized into themes by two independent Vietnamese-speaking individuals. A third researcher, also fluent in Vietnamese, checked and compared the spread sheets for accuracy and reliability. Results: Nearly all participants reported being negatively affected by the oil spill disaster. They described loss of income (59\%), loss of employment (27\%), and inability to pay bills (12\%). High levels of stress, anxiety and depression, as well as an increase in behavioral problems were reported. None of the participants claimed to know where or how to seek help for mental health problems. Conclusions: The oil spill disaster has had significant negative consequences for the economic well-being, family functioning, and behavioral and mental health status of the Vietnamese American gulf coast communities. Implications and strategies for working with this population are offered.

Keywords: Mental Health; Cultural Competency; Vietnamese-Americans; BP Oil Spill; Effective Strategies

\section{Introduction}

In recent years, the Vietnamese Gulf Coast communities have endured multiple natural, as well as man-made disasters. The largest and third strongest hurricane ever recorded to make landfall on US soil was hurricane Katrina, which occurred in 2005. Hurricane Katrina impacted about 90,000 square miles across the Gulf Coast States; the death toll mounted to more than 1500 in Louisiana and 238 in Mississippi alone. The hurricane affected over 15 million coastal residents in a variety of ways, such as economic loss, loss of employment, property damage, unprepared forced evacuation, scarcity of fuel, and food and water contamination (Wikipedia, 2013), with resulting high rates of symptoms of post-traumatic stress disorder and depression among Vietnamese Americans (Norris, Van Landingham, \& Vu, 2009). Approximately 250,000 people were forced to evacuate; although many returned to their ruined or

\footnotetext{
*Corresponding author.
}

demolished homes and communities, others decided to rebuild their lives elsewhere.

A more recent devastating disaster was the Deepwater Horizon Oil Spill (aka the Gulf or BP Oil Spill) that occurred in the Gulf of Mexico on April 20, 2010. The initial oil rig explosion killed 11 people and injured 17 others; more than 200 million gallons of crude oil were released into the Gulf of Mexico; 16,000 miles of coastline were affected, including the coasts of Alabama, Florida, Louisiana, Mississippi, and Texas; of the 400 miles of Louisiana coast, approximately 125 miles were polluted by the oil spill (News-Basics, 2010). Given such widespread damage, President Barrack Obama announced, "this oil spill is the worst environmental disaster America has ever faced" (Oval Office, 2010). Oil spills differ from natural disasters in a number of ways (Palinkas, 2012). First there is a longer period of acute stress; in addition there are devastating effects on the social fabric, disrupting community networks of support, and thirdly, persons experience greater anxiety because 
such events are less common than natural disasters (Palinkas, 2012). Although it has been more than three years since the gulf oil spill, the long-term damage to the economic and psychological well-being of the people who are dependent on the fisheries and seafood industry in this region remains unknown.

The Vietnamese population in the coastal region has been somewhat neglected, due, in part, to their lack of political voice and absence of advocacy for resources. While the needs for mental health intervention are high, there are no culturally and linguistically sensitive services available. Additionally, due to the lack of understanding of the Vietnamese culture, mainstream professionals are unable to effectively reach out to this underserved population. The objective of this paper was to provide the readers a better understanding of the Vietnamese coastal residents, reveal their mental health needs in the face of the oil spill, and to offer recommendations on culturally-sensitive strategies for working with this underserved population.

The qualitative data were collected during focus groups conducted by the first author, following methods and procedures successfully used by other researchers (e.g., Bloor, Frankland, Thomas, \& Robson, 2001; Legerski, Vernberg, \& Noland, 2012).

The background of Vietnamese American communities in the gulf coastal states provides a context for the study. Vietnamese Americans only began to resettle in the United States in 1975, when Saigon (South Vietnam) fell to the Communist regime. With the current population of more than 1.5 million (Nguyen, 2011), Vietnamese individuals live in virtually every state. However, the vast majority of the population has chosen to resettle in mild-weathered states, with California and Texas being the top two states comprising the highest concentration of Vietnamese American populations, respectively. Several reasons have been identified for their choice of resettlement. First, many chose to live in the coastal region due to its subtropical climate, which is similar to the weather they grew up with in Vietnam. Second, the Vietnamese communities of the West and Gulf Coast regions (except for Alabama (AL), Mississippi (MS), and Louisiana (LA)) are better established with regard to infrastructure for economic, legal, and social services, and health care support for Vietnamese-speaking individuals. Also, many chose the Coastal region to continue the fishing and shrimping traditions they brought from their native country. For thousands of individuals whose language literacy is limited, the seafood industry has allowed them job opportunities to start a new life and to take care of their families. When asked directly why they chose this profession, the response was usually, "you don't need to speak English to catch fish or shrimp; besides this is the only thing that I know all my life." Yet, a large number of Vietnamese individuals moved to New Orleans due to the attraction of the Catholic tradition. In the early 1980s, the New Orleans Archdiocese was particularly supportive of Vietnamese Roman Catholics. Thus, many Vietnamese relocated to this area to build a tight knit Catholic community or village. As a result, New Orleans is the home of many Vietnamese Catholic parishes, with Mary Queen of Vietnam being the largest.

From the seafood industry standpoint, the Coastal states that were impacted most severely by the aforementioned disasters included Alabama, Mississippi, and Louisiana. According to the US Census (2010), there are approximately 42,775 Vietnamese Americans resettled throughout these Coastal states (28,352 in Louisiana; 7025 in Mississippi; and 7398 in Alabama). Approximately, $30 \%-50 \%$ of all seafood-industry workers in the Gulf region are Vietnamese ethnic in origin. Boat People SOS has estimated that approximately 70\% - 80\% of Vietnamese workers across the Gulf Coast of Alabama, Mississippi, and Louisiana, are associated with the seafood industry. Many of these individuals have worked as fishermen, shrimpers, deck hands, shrimp packers, oyster shuckers and crab pickers since resettling in the US. For many, the traditions of fishing and shrimping were handed down to them from previous generations. The hurricanes and BP Oil Spill disaster in the recent years have turned their livelihoods upside down and put them in a limbo situation. Many lost their hard-earned boat vessels, either due to damage from the hurricanes or to foreclosure from being unemployed after the BP Oil Spill. Furthermore, changing jobs or acquiring new technical skills is not an option for many individuals, due to their cultural and language barriers.

Past reports have documented that many Vietnamese refugees had experienced a multitude of traumatic experiences before arriving in the United States. These traumas may include war atrocities, family disintegration, communist "reeducation" (i.e., imprisonment), being lost at sea, being attacked by pirates, being starved, being ill without medical care, being sexually assaulted by pirates, and witnessing death of friends or loved ones (US Committee for Refugees, 1984; Mollica, Wyshak, \& Lavelle, 1990). While man-made and natural disasters can be traumatic for anyone, individuals with histories of past trauma are particularly vulnerable to mental health and adjustment problems (Teodorescu, Heir, Hauff, Wentzel-Larsen, \& Lien, 2012). Repeated or retraumatization has been identified as a serious mental health risk and treatment tends to be highly complex and difficult (Courtois \& Ford, 2009). Given that many Vietnamese individuals came to the US with a history of a multitude of past traumatic experiences (Ngo, Tran, Gibbons, \& Oliver, 2001) the re-traumatization experiences through these disasters may put them at an increased risk for a host of behavioral and mental health problems.

The Vietnamese communities in the Coastal States (AL, MS, and LA) have demographic characteristics that are quite different from the well-established Vietnamese communities in other States such as California, Massachusetts, or Texas. First, the Vietnamese community in the Gulf Coast region lacks the social support and culturally sensitive health care infrastructure. For example, there are limited Vietnamese speaking advocacy or social service organizations to assist victims of disasters. Although, faith-based organizations have been the main frontrunners in extending helping hands, they are not equipped with the specialty knowledge and skills to effectively deliver mental health support. Additionally, during the times of crises, there are virtually no Vietnamese-speaking mental health professionals to provide crises intervention to the victims of disasters. Furthermore, Vietnamese-speaking general practitioners are also scarce for residents in the cities of Biloxi, MS and Bayou La Batre, AL. Despite the great needs for social and mental health services among the Vietnamese community in the Gulf region, mainstream agencies are not equipped with the cultural sensitivity and language skills to reach out to this underserved population.

\section{Method}

\section{Participants}

Sixty Vietnamese adults across the three States participated in 
the focus group study. Of this number, 39 (65\%) were females, with an age range from 28 - 65 years. Participants were eligible for inclusion if they were at least 18 years of age or older, were a resident of the state where the focus group was held, and spoke fluent Vietnamese. On average, participants had had about 8 years of education in Vietnam, with the number of years ranging from 3 - 12 years. With regard to marital status, $86 \%$ were married, $10 \%$ were single, and $4 \%$ were divorced/ separated. Approximately $77 \%$ reported working in the seafood industry. The type of work related to Seafood Industry included shrimpers, deck hands, shrimp packers, and oyster shuckers. About 92\% (55/60) reported that they spoke English "not very well”. See Table 1.

\section{Materials}

Four primary questions framed the focus group discussion. Those questions and the resulting discussions were in the Vietnamese language. 1) What impact did the Oil Spill have on you and your family? 2) Did you notice any changes in your health (or members of your family's health; including mental health) or behavior within the past month? 3) What are the health/ mental health resources that are available in your area? 4) What are some of the major barriers you faced in dealing with the disaster?

\section{Procedure}

Participants who had received advocacy or other social services from a Vietnamese non-profit organization (Boat People SOS) were recruited from AL (Bayou La Batre), MS (Biloxi), and LA (New Orleans). A supporting staff from each city randomly called up the clients and invited them to participate in the focus group meetings. One focus group was conducted in each city by the first author. The number of participants in each group ranged from 17 - 22 persons. The group meetings were

Table 1.

Demographics of focus group participants $(\mathrm{N}=60)$.

\begin{tabular}{lcc}
\hline Number of Participants & $\%$ & Mean (SD) \\
\hline Total Sample & 60 & \\
$\quad$ Bayou La Batre (AL) & 22 & \\
Biloxi (MS) & 17 & \\
$\quad$ New Orleans (LA) & 21 & 37 years (SD = 6) \\
Gender & $65 \%$ (female) & \\
Age & & \\
Education & & \\
Marital Status & & \\
$\quad$ Married & $86 \%$ & 3 ) \\
$\quad$ Single (never married) & $10 \%$ & \\
$\quad$ Divorced/separated & $4 \%$ & \\
Employment Type & \\
$\quad$ Seafood & $77 \%$ \\
Casino/Hotel & $10 \%$ \\
$\quad$ Restaurant & $5 \%$ \\
Nails & $5 \%$ \\
Other & $3 \%$ \\
English Proficiency & $92 \%$ (not very well) & \\
\hline
\end{tabular}

held at a neutral place (i.e., at the BPSOS office) and lasted about two hours. Prior to the focus group discussion, each participant completed a short demographic form and signed a consent form to be audio recorded. Participation was completely voluntary. Participants had the option to decline or to withdraw from the discussion at any time. The audiotapes were transcribed verbatim by two independent coders fluent in Vietnamese.

\section{Coding}

The responses from each participant were typed into a spreadsheet for content analysis and comparison across participants. The responses were then grouped together under the heading of each of the four questions discussed. Once the process of categorizing responses was completed, a third person, also fluent in Vietnamese, reviewed the spreadsheet for similarities and consistency across the two coders. Results indicated that the two coders were in agreement at a rate of nearly $100 \%$.

\section{Results}

\section{Question 1: What Impact Did the Oil Spill Have on You and Your Family?}

To this question, the following themes were reported: reduction in work hours/income 58.33\% (35/60); loss of employment $26.66 \%$ (16/60); unable to pay bills $11.66 \%$ (7/60), and family separation $3.33 \%$ (2/60). Overall, every participant in the focus group across the three States reported that their household income was impacted to some degree. Individuals who own smaller boat vessels were no longer able to shrimp due to the disappearance of these species after the Oil Spill. Additionally, they indicated that the fuel cost is significantly higher than the net profit. One man stated, "I have been shrimping in this water for more than 25 years; on a bad trip, I could still make about $\$ 1500$ - \$2000/week in net profit. On the last three trips, we came home with a negative income, not making enough to cover the fuel cost. Furthermore, the prices of the shrimp had fallen drastically during this period. I have bills that must be paid. I might lose my boat soon.” The participants across the three States concurred that they, too, are short or late on paying their bills. The effects on household income not only affected boat owners but also trickled down to hired captains, deck hands, oyster shuckers, and seafood processing workers. Family unity was also affected. Two participants, one from Biloxi and one from New Orleans, indicated that they had to relocate their children to live with relatives in another state so their children could continue to go to school.

\section{Question 2: Have You Noticed Any Changes in Your Health (Including Mental Health) or Behavior within the Past Month?}

To this question, the following themes were reported: increase in anxiety and depression-common symptoms included "worrying all the time, having poor appetite, difficulty falling or staying asleep, feeling tense and irritable, feeling weak and fatigue, losing interest in daily activities, and feelings of body aches and indigestion." These are somatic symptoms commonly associated with Anxiety and Major Depressive Disorders documented among Asian individuals (e.g., Kalibatseva \& Leong, 2011). 
All participants across the three States raised their hands to indicate that they had experienced several of these symptoms regularly over the past two weeks. Two participants reported that, "I have not been able to sleep in two days." Thoughts about the unknown future of the seafood business were daunting for many Vietnamese. The vast majority of the Vietnamese Coastal residents is dependent on the seafood industry for its livelihood and feared that the seafood will disappear indefinitely. One lady in Bayou La Batre stated, "I have been shucking oysters for 13 years. Although this is a hard job, I do not know English well enough to learn any other trades. I had been dependent on this job to raise my three children. My husband is a deckhand and is currently out of job. My work hours had been cut from 9 hours/day to just 4 hours/day and on some days they don't even call me in to work. I don't know how long this will continue." This sentiment resonated among all participants in all three states. The stress associated with losing their employment and income also led to behavioral problems and maladaptive coping. A female participant in Biloxi indicated that her husband has been drinking and smoking more than usual. Another woman reported that with more idle time at home, her husband had been visiting the Casinos more often. She added, "I just hope that he doesn't gamble away the little money we have left." Marital conflict was also an important topic that the group members brought up for discussion. Several women from Bayou La Batre stated that they knew of someone in the community who was battered after the husband lost his job as a deckhand.

\section{Question 3: What Are the Health/Mental Health Resources That Are Available in Your Area?}

The mental health question was rephrased as "What resources are available to help you deal with the stress symptoms?" The decision to rephrase this question was to make it sound less stigmatizing and less threatening to the participants. To this question, nearly all participants indicated that they did not know of any available resources for Vietnamese-speaking individuals in their local area. To deal with these psychosocial stressors, participants indicated that they get together for support. However, informal support from friends and neighbors could lead to more problems. Because the Vietnamese communities in the Gulf region are fairly small, confidential information about personal problems could leak out into the community and become the topic for rumor. One lady in Biloxi stated, "People in this area know each other. Therefore, we don't really talk about personal family matters. Other people may use that information in a negative way. So we just keep quiet."

Of the 60 participants, only two people reported that they had health insurance because they could afford it as boat owners. At the focus group in Biloxi, when asked, "What do you do if you became very sick?” A moment of silence filled the room. Suddenly, a voice in the back of the room said loudly, "We just endure it until the sickness go away and hope that we don't die." The room was then filled with laughter again.

\section{Question 4: What Are Some of the Major Barriers You Faced in Dealing with the Disaster?}

Perhaps the most challenging barrier faced by the majority of the participants was the lack of English proficiency. Among this sample, 55 out of 60 (92\%) individuals self-reported that their English skills in the areas of Reading, Writing, and Speaking/Understanding were "not very well”. Three individuals (5\%) reported they neither write nor read Vietnamese "very well”. Ninety seven percent of the sample reported they did not receive the news directly from mainstream media outlets or from the official website about the disasters. Nearly $100 \%$ reported they were late in receiving the news about the financial claim process published by the Gulf Coast Claims Facility. The participants expressed that "we are at a disadvantage due to our inability to read or hear English". There was a general consensus among the participants across the three states that initially they did not know where or how to file the claims for their financial loss as a result of the Oil Spill disaster. All of them attributed this to a lack of English proficiency.

Due to their limited English proficiency, Vietnamese Coastal residents tend to congregate into a tight knit community for support. For this reason, the community is somewhat segregated from the mainstream social support network. Furthermore, with the lack of language and cultural knowledge, mainstream agencies are struggling with delivering culturally sensitive services to the Vietnamese population. In response to the hurricanes and the Oil Spill disaster, limited national and state resources were allocated to assist victims of disasters. However, due to cultural and language barriers, many Vietnamese did not receive the benefits they rightfully deserved or needed. Additionally, the absence of a political voice within the community and the lack of advocacy, also placed the community at a disadvantage in fighting for these limited resources.

\section{Discussion}

One objective of this paper was to present the qualitative data on the perceived impact of the BP Oil Spill, the mental health needs, and mental health resources among the Vietnamese Coastal communities. A second objective was to offer practical and culturally sensitive recommendations for mainstream health care and service providers in order to effectively reach out and work with the Vietnamese population.

The results revealed that the BP Oil Spill had a significant negative impact on the participants' household income in various ways. This negative impact affected not only family connectedness but also placed the participants at an increased risk for mental health and behavioral health problems. The repercussions reported by participants fell into the three tiers of the mental health impacts of oil spills of Palinkas' conceptual model (2012). We found economic impacts, consistent with Tier I, increased social conflict and reduced social support of Tier II, and signs of anxiety, depression, and somatic symptoms, intrapersonal impacts of Tier III. The somatic symptoms are consistent with past reports that Asian individuals may express psychological symptoms in a somatic manner (Mumford, 1992; Kalibatseva \& Leong, 2011). It should be noted that man-made or natural disasters may be stressful and traumatic for anyone; but that the Vietnamese coastal population is particularly at risk for mental health problems due to their past experiences of repeated traumatization prior to coming to America, including war, imprisonment, torture, and refugee experiences, their exposure to hurricane Katrina, and now the oil spill disaster.

In addition to mental health symptoms, participants also acknowledge signs of behavioral health issues. Although marital discord and domestic violence was not fully examined in the 
discussion, participants were concurred that the stress associated with the oil spill does contribute to the strain of their spousal relationship. One female participant from Biloxi explained that, "my husband and I argued more and more because he has so much free time doing nothing." While domestic violence is an undeniable fact within the Vietnamese community, it often occurs in private and hidden behind the public view (personal conversation with Coi Nguyen, a Domestic Violence case worker in the Gulf Coast).

Another behavioral health problem that might be exacerbated by the stress related to the Oil Spill is gambling. Pathological gambling is a huge problem among the Asian communities and has been widely documented (e.g., Blaszczynski, Huynh, Dumlao, \& Farrell, 1998; Ethnic Communities' Council of NSW, 1999; Petry, Armentano, Kuoch, Norinth, \& Smith, 2003). The city of Biloxi, MS is home to at least nine first-class casinos and resorts (http://www.biloxi.ms.us/casinos/). Every participant in the focus group across the three States agreed that gambling is a serious problem for many Vietnamese individuals in the community. During an interview, Danny Le, Branch Manager for BPSOS in Biloxi, "this [gambling issue] is a serious problem that we don't know how to handle." Over the past several years, a number of people have sought assistance from his office after losing their life savings. During the initial needs assessment survey, the first author came across a case in which a Vietnamese woman lost her family after she gambled away more than $\$ 100,000$ of her husband's hard earned income. The psychosocial stressors associated with the Oil Spill may exacerbate the gambling behavior, which is already a problem in this vulnerable population.

Despite the mental health needs that exist in the Vietnamese community, the available resources (e.g., Vietnamese-speaking mental health professionals) to meet these needs are nonexistent. The lack of mental health resources may cause a delay in treatment, which may exacerbate the severity of the condition over time. Interview information obtained from faith-based and social service organizations revealed a serious lack of culturally and linguistically sensitive mental health services for the Vietnamese population. Although mainstream agencies are trying to reach out to the Vietnamese community, they, too, are not culturally competent to work with Vietnamese-speaking clients.

One hallmark of the Vietnamese culture is a strong emphasis on family unity and connectedness. Thus, when family members are separated due to an uncontrollable event, it is a devastating experience for the whole family as a unit. In our sample, at least two families reported that they had to send their children to another state to live with relatives in order to continue with schooling.

Past studies have documented that limited English proficiency was associated with poor adaptation and health problems among refugees and immigrants (Okafor, Carter-Pokras, Picot, \& Zhan, 2013; Nguyen \& Benet-Martínez, 2013). Poor English proficiency also limits Vietnamese individuals in their search for jobs, as most require adequate command of the English language. Many of those individuals have held only one type of job (e.g., oyster shucking) since their resettlement in the US. Thus, it would be quite difficult for them to adapt to new skills training or a job change. English skills have been used effectively as a good indicator of adaptive acculturation and have been found to mediate the impact of trauma on depression and PTSD (Ngo et al., 2001). Ninety two percent (92\%) of the sample in this study indicated that their English skills were "not very well.” This is a much higher statistic than the national average (54\%) reported by the Vietnamese American population (US Census, 2010). Poor English proficiency also exacerbated the stress level for many Vietnamese individuals in the Gulf region since it blocked their ability to access accurate news regarding the claims process in a timely manner.

\section{Recommendations}

The following recommendations are made to assist health care providers to effectively work with the Vietnamese population. For some additional cultural advice on working with Vietnamese Americans after disasters, see also Kaplan and Huynh (2008). It is important to be aware that the path toward becoming a culturally competent practitioner is a developmental process. Furthermore, to become a culturally competent practitioner one must practice compassion, be open, have a positive attitude, and develop new and effective skills, as well as keep up with current information and knowledge about the population one serves.

- Seek to learn the history and immigration experiences of the Vietnamese population. Vietnamese people are very proud of their history as it relates to their longstanding struggle and resilience against foreign colonization and civil wars. Furthermore, their journey in search for freedom was often marked by horrific traumatic experiences. Understanding their history and exploring their immigration experiences could be, in and of itself, very therapeutic and an excellent way to build rapport.

- Offer help and direct individuals and families to appropriate resources. Vietnamese individuals are indeed a very proud group of people. It is unlikely that they would outwardly ask for help, even though they really need the assistance. It is customary in the Vietnamese culture to offer support before the person has to voice her/his needs. Oftentimes, the offer must be made several times and the person may decline repeatedly before s/he accepts the offer.

- Create a trusting and collaborative network with community leaders, faith-based leaders, health care professionals (including indigenous healers), and social service organizations that specifically serve the Vietnamese-speaking population. In order to reach out to the Vietnamese community, it is critical that an agency or service provider fully secure the support of these individuals. When approaching these community leaders, it is important to explain what services you have to offer and solicit their help in delivering these services to the people. The trusting relationship that you seek to build with the people begins with the people in the leadership positions within the community.

- Become familiar with Vietnamese health care customs and attitudes toward mental health. For example, preventive medicine is not a top priority for many Vietnamese individuals. Furthermore, many do not have health care insurance coverage. Thus, they often delay seeking help for their illness until the condition becomes unbearable. For mental health problems, the matter is usually dealt with within the family circle. The patient is usually shielded or hidden from public view due to the fear of ruining the family's name. Vietnamese women are known for their self-sacrifice for the sake of the family. Thus, a woman may suffer in silence in order to maintain harmony for her family. For this reason, depression may never be spoken of or even perceived as an 
illness that needs professional intervention.

- Become familiar with home health remedies. Almost every Vietnamese family practices some form of home health remedy for common ailments such as flu, fever, allergies, indigestion, muscle aches, stomach aches, etc. One of the most common home health practices is "coining" or "cao gio". Coining (cao gio) involves rubbing medicinal oil on the body parts that are believed to be affected by the illness (usually the neck, back, chest, arm, and the temples). Once a light coating of the oil is applied, the affected or target area would be lightly rubbed repeatedly with a coin or spoon. This action causes the skin to change color and leaves prominent dark reddish marks on the affected areas. These marks last between three to seven days. Usually no physical pain is associated with coining. After the procedure, the person (client/patient) usually reports some kind of immediate relief. To the naïve observer, these marks may look like signs of physical abuse. Thus, it is important to become familiar with the various forms of home health remedies practiced by the Vietnamese people to avoid making false assumptions about a behavior or practice unfamiliar to one's culture.

- Become familiar with indigenous health care practices and pattern of medication usage. First, many Vietnamese adhere to the belief that Western medicine is harmful to their liver or stomach if taken for an extended time. For this reason, many people change their treatment regimen to herbal medicines without informing their primary doctor. Second, many Vietnamese individuals, especially elderly individuals, often share medicines that they believe work for them. Thus, it is common for Mrs. A to share her headache medications with Mr. B because she responded well to a particular type of medication. Finally, many traditional Vietnamese individuals are more familiar and comfortable with alternative treatment methods, such as acupuncture. For these reasons, recommendations for treatment must consider incorporating both Eastern and Western treatment methods to facilitate cooperation by the client/patient.

\section{Conclusion}

Despite the fact that the Vietnamese-American population has continued to grow into the 21st century (US Census, 2010), research on the mental health issues among this population remains scarce. The recent hurricane and the BP Oil Spill have put the Vietnamese communities in the Gulf Coastal region at an increased risk for behavioral and mental health problems. In particular, the BP Oil Spill has caused a negative economic impact among many Vietnamese families, produced high levels of distress, and interrupted family functioning. While the mental health needs are high, resources to address these needs are nonexistent in the coastal region. Barriers that prevented early intervention included poor English skills, cultural barriers, and lack of resources. Additionally, mainstream health care providers are struggling to deliver culturally competent services to this underserved population. The objective of this paper is to present qualitative findings on the perceived impact of the BP Oil Spill, identify the mental health needs, and document the lack of mental health resources to meet the needs of the Vietnamese Gulf Coastal communities. Finally, the recommendations presented in this paper may be helpful to mainstream service providers who are passionate about delivering effective services to this population.

\section{Author Notes}

Shortly after the BP Oil Spill, D. N. was hired as a mental health consultant by the American Red Cross to work in the Gulf Coast. During the three months he was there, he organized, developed, and delivered Psychological First Aid workshops to Vietnamese residents, as well as to community and faith-based leaders. In the beginning of 2011, he partnered with Boat People SOS - a Vietnamese-American non-profit advocacy organization-to work on various mental health projects funded by the Department of Mental Health in the states of Mississippi, Alabama, and Catholic Charities of New Orleans. Over the past two and a half years, he has delivered numerous psycho-educational workshops addressing topics such as mental health, coping with stress, domestic violence, and addictive behaviors to more than 500 Vietnamese participants across these three Coastal states. He also conducted multiple Cultural Competency Workshops and trained more than 200 mainstream public servants and health care workers throughout the states of AL, MS, and LA. This paper draws from his initial needs assessment of the community and from focus group studies he conducted in 2010.

\section{REFERENCES}

Blaszczynski, A., Huynh, S., Dumlao, V. J., \& Farrell, E. (1998). Problem gambling within a Chinese speaking community. Journal of Gambling Studies, 14, 359-380. http://dx.doi.org/10.1023/A:1023073026236

Bloor, M., Frankland, J., Thomas, M., \& Robson, K. (2001). Focus groups in social research. Thousand Oaks, CA: Sage Publications.

Courtois, C. A., \& Ford, J. D. (2009). Treating complex traumatic stress disorders: An evidence-based guide. New York, NY: Guilford.

Ethnic Communities' Council of NSW (1999). Gambling among members of ethnic communities in Sydney (GAMECS) project part 3Report on problem gambling and ethnic communities forum. http://www.olgr.nsw.gov.au/pdfs/ECC_\%20Forum.pdf

Kalibatseva, Z., \& Leong, F. T. L. (2011). Depression among Asian Americans: Review and recommendations. Depression Research and Treatment, 2011, 9 p. http://dx.doi.org/10.1155/2011/320902

Kaplan, A. S., \& Huynh, U. K. (2008). Working with Vietnamese Americans in disasters. In A. J. Marsella, J. L. Johnson, P. Watson, \& J. Gryczynski (Eds.). Ethnocultural perspectives on disasters and trauma (pp. 321-349). New York: Springer.

Legerski, J.-P., Vernberg, E. M., \& Noland, B. J. (2012). A qualitative analysis of barriers, challenges, and successes in meeting the needs of Hurricane Katrina evacuee families. Community Mental Health Journal, 48, 729-740.

http://dx.doi.org/10.1007/s10597-011-9446-1

Mollica, R. F., Wyshak, G., \& Lavelle, J. (1990). Assessing symptom change in Southeast Asian refugee survivors of mass violence and torture. American Journal of Psychiatry, 147, 83-88.

Mumford, D. B. (1992). Detection of psychiatric disorders among Asian patients presenting with somatic symptoms. British Journal of Hospital Medicine, 47, 202-204.

News-Basics (2010). Oil spill in the gulf. http://news-basics.com/2010/oil-spill-in-the-gulf/

Ngo, D., Tran, T. V., Gibbons, J. L., \& Oliver, J. M. (2001). Acculturation, premigration, traumatic experiences, and depression among Vietnamese Americans. Journal of Human Behavior in the Social Environment, 3, 225-242. http://dx.doi.org/10.1300/J137v03n03 14

Nguyen, A.-M.T.D., \& Benet-Martínez, V. (2013). Biculturalism and adjustment: A meta-analysis. Journal of Cross-Cultural Psychology, 
44, 122-159.

http://dx.doi.org/10.1177/0022022111435097

Nguyen, T. A. (2011). The Vietnamese population in the United States: 2010.

http://www.bpsos.org/mainsite/images/DelawareValley/community pr ofile/us.census.2010.the\%20vietnamese\%20population_july\%202.201 1.pdf

Norris, F. H., Van Landingham, M. J., \& Vu, L. (2009). PTSD in Vietnamese Americans following Hurricane Katrina: Prevalence, patterns, and predictors. Journal of Trauma and Stress, 22, 91-101.

http://dx.doi.org/10.1002/jts.20389

Okafor, M. T., Carter-Pokras, O. D., Picot, S. J., \& Zhan, M. (2013). The relationship of language acculturation (English proficiency) to current self-rated health among African immigrant adults. Journal of Immigrant and Minority Health, 15, 499-509.

http://dx.doi.org/10.1007/s10903-012-9614-6

Oval Office (2010). Remarks by the president to the nation on the BP oil spill.

http://www.whitehouse.gov/the-press-office/remarks-president-natio $\underline{\text { n-bp-oil-spill }}$
Palinkas, L. A. (2012). A conceptual framework for understanding the mental health impacts of oil spills: Lessons from the Exxon Valdez oil spill. Psychiatry, 75, 203-222.

http://dx.doi.org/10.1521/psyc.2012.75.3.203

Petry, N. M., Armentano, C., Kuoch, T., Norinth, T., \& Smith, L. (2003). Gambling participation and problems among South East Asian refugees to the United States. Psychiatric Services, 54, 1142-1148. http://dx.doi.org/10.1176/appi.ps.54.8.1142

Teodorescu, D.-S., Heir, T., Hauff, E., Wentzel-Larsen, T., \& Lien, L. (2012). Mental health problems and post-migration stress among multi-traumatized refugees attending outpatient clinics upon resettlement to Norway. Scandinavian Journal of Psychology, 53, 316-332.

http://dx.doi.org/10.1111/j.1467-9450.2012.00954.x

US Committee for Refugees (1984). Vietnamese boat people: Pirates' vulnerable prey. Washington DC: American Council for Nationalities Service.

Wikipedia (2013,) Hurricane Katrina. http://en.wikipedia.org/wiki/Hurricane_Katrina 